\title{
Unmet needs in the management of cardiovascular risk in inflammatory joint diseases
}

\section{Santos Castañeda, Esther F. Vicente-Rabaneda, Noelia García-Castañeda, Diana Prieto-Peña, Patrick H. Dessein \& Miguel A. González-Gay}

To cite this article: Santos Castañeda, Esther F. Vicente-Rabaneda, Noelia García-Castañeda, Diana Prieto-Peña, Patrick H. Dessein \& Miguel A. González-Gay (2019): Unmet needs in the management of cardiovascular risk in inflammatory joint diseases, Expert Review of Clinical Immunology, DOI: 10.1080/1744666X.2019.1699058

To link to this article: https://doi.org/10.1080/1744666X.2019.1699058

Accepted author version posted online: 28 Nov 2019.

Submit your article to this journal $[\pi$

Q View related articles $\longleftarrow$

View Crossmark data \lceil 
Publisher: Taylor \& Francis \& Informa UK Limited, trading as Taylor \& Francis Group

Journal: Expert Review of Clinical Immunology

DOI: $10.1080 / 1744666$ X.2019.1699058

\section{Unmet needs in the management of cardiovascular risk in inflammatory joint diseases}

Authors: Santos Castañeda ${ }^{1,2^{*}}$, Esther F. Vicente-Rabaneda ${ }^{1}$, Noelia García-

Castañeda $^{1}$, Diana Prieto-Peña ${ }^{3}$, Patrick H. Dessein ${ }^{4}$, Miguel A. González-Gay ${ }^{3,5,6}$

\section{Affiliations:}

${ }^{1}$ Reumatology Division, Hospital Universitario de La Princesa, IIS-Princesa, Madrid, Spain.

${ }^{2}$ Cátedra UAM-ROCHE, EPID Future, Universidad Autónoma de Madrid (UAM), Madrid, Spain.

${ }^{3}$ Division and Epidemiology, Genetics and Atherosclerosis Research Group on Systemic Inflammatory Diseases, Rheumatology Division, Hospital Universitario Marqués de Valdecilla, IDIVAL, Santander, Spain.

${ }^{4}$ Honorary Research Professor, School of Physiology and School of Clinical Medicine, Faculty of Health Sciences, University of Witwatersrand, Johannesburg, South Africa.

${ }^{5}$ School of Medicine, University of Cantabria, Santander, Spain.

${ }^{6}$ Cardiovascular Pathophysiology and Genomics Research Unit, School of Physiology,

Faculty of Health Sciences, University of Witwatersrand, Johannesburg, South Africa.

\section{*Correspondence to:}

Santos Castañeda, MD, PhD. Rheumatology Division, Hospital de La Princesa, IIS-Princesa, c/ Diego de Leon 62, 28006-Madrid, SPAIN

Phone number: + (34) 915202200 (ext. 2473) 
E-mail: scastas@gmail.com

santos.castaneda@salud.madrid.org

Running title: Unmet needs in CV management of IJD

\begin{abstract}
Introduction: Increased cardiovascular $(\mathrm{CV})$ morbidity and mortality is observed in inflammatory joint diseases (IJDs) such as rheumatoid arthritis, ankylosing spondylitis and psoriatic arthritis. However, the management of $\mathrm{CV}$ disease in these conditions is far from being well established.

Areas covered: This review summarizes the main epidemiologic, pathophysiological and clinical risk factors of CV disease associated with IJDs. Less common aspects on early diagnosis and risk stratification of the $\mathrm{CV}$ disease in these conditions are also discussed. In Europe, the most commonly used risk algorithm in patients with IJDs is the modified SCORE index based on the revised recommendations proposed by the EULAR task force in 2017.

Expert opinion: Early identification of IJD patients at high risk of CV disease is essential. It should include the use of complementary non-invasive imaging techniques. A multidisciplinary approach aimed to improve heart-healthy habits, including strict control of classic $\mathrm{CV}$ risk factors is crucial. Adequate management of the underlying IJD is also of main importance since reduction of disease activity decreases the risk of $\mathrm{CV}$ events. Non-steroidal anti-inflammatory drugs may have a lesser harmful effect in IJD than in the general population, due to their antiinflammatory effects along with other potential beneficial effects.
\end{abstract}

Keywords: ankylosing spondylitis, cardiovascular disease, cardiovascular risk factors, inflammatory joint diseases, prevention, psoriatic arthritis, rheumatoid arthritis. 


\section{Article Highlights}

- The prevalence of CV morbidity and mortality in IJDs is increased compared to that in general population.

- Besides genetics, traditional CVRFs and those related to the inflammatory disease, there are other psychosocial and emergent factors that can negatively influence the occurrence of CVD events in patients with IJD.

- Current risk chart algorithms used to determine the CV risk of the general population usually underestimate the actual CV risk of patients with IJD.

- The EULAR task force recommends calculating the CV risk of patients with RA by multiplying the risk obtained using CV risk charts by 1.5 . The applied model may be possibly extrapolated to other IJDs.

- Strict adherence to national and international guidelines for $\mathrm{CV}$ risk management is recommended, especially regarding the control of traditional CVRFs, for the prevention of new CV events.

- The 2019 recommendations for the management of dyslipidemias focused on tight control of lipid levels in patients with high or very high CV risk. 


\section{Introduction}

The term inflammatory joint diseases (IJD) encompasses a group of chronic inflammatory diseases such as rheumatoid arthritis (RA), ankylosing spondylitis (AS) and psoriatic arthritis (PsA). IJD mainly affect the joints of the axial or peripheral skeleton and are associated with a wide spectrum of extra-articular manifestations that depend on the type of disease. They also share a set of common comorbidities, predominantly cardiovascular (CV), mood disorders (anxiety and depression), infection, cancer, bone loss, and liver, gastrointestinal and kidney alterations [1,2*-4]. RA is a chronic systemic autoimmune and inflammatory disease which characteristically affects diartrodial synovial joints leading to joint damage and physical disability [5*]. AS is included in the group of spondyloarthritis $(\mathrm{SpA})$ that also comprises forms of atypical AS without radiographic manifestations (non-Rx $\mathrm{SpA}$ ), reactive arthritis, PsA and other arthropathies associated to inflammatory bowel disease. PsA is characterized by synovial and entheseal inflammation and psoriasis. The clinical presentation of joint disease in PsA is heterogeneous and can vary from peripheral arthritis to asymmetrical oligoarthritis or axial forms similar to AS. Cardiovascular comorbidity is by far the most significant morbidity in these conditions, due to its frequency and impact on patient's survival and quality of life. In fact, subclinical CV disease (CVD), CV events (CVE) and mortality are increased in IJD, as a consequence of a common process of endothelial damage and accelerated atherosclerosis $[\mathbf{6 - 8 , 9 * *}$. The excess of CV morbidity observed in these patients $[\mathbf{1 0 , 1 1 ]}$ is the result of a combined effect of traditional CV risk factors (CVRFs), chronic inflammation and a genetic component that has more extensively been studied in RA $[12 *, 13,14]$. Indeed, RA was considered as the paradigm condition in terms of 
$\mathrm{CV}$ disease and $\mathrm{CV}$ comorbidity, due to the amount and quality of information on this issue. For this reason, RA will serve as the guide disease for this revision.

In this review we will focus on both well-known aspects of the CV disease in IJD, more specifically RA, AS and PsA, and those features that require further research as well as in the "unmet needs" in this field nowadays.

\section{Areas covered}

\subsection{Epidemiology of cardiovascular disease in IJD}

The risk of atherosclerotic CVD in IJD, in particular in RA, AS and PsA is increased compared to the general population $[\mathbf{9 * *}, \mathbf{1 1}, \mathbf{1 2} *]$. In a cross-sectional study conducted in Spain, the prevalence of CVD in a cohort of IJD was increased compared to a cohort of non-inflammatory subjects [15]. Mortality due to CVD in IJD is also increased when compared to the general population [ $9 * *]$.

More specifically, the risk of CVD in RA is comparable to that of type 2 diabetes mellitus (DM2), which translates into an increase in premature mortality due to CV events $[\mathbf{1 0 , 1 1 , 1 2 * , 1 6 ] . ~ A ~ m e t a - a n a l y s i s ~ m a d e ~ a ~ f e w ~ y e a r s ~ a g o ~ s h o w e d ~ t h a t ~ C V ~}$ mortality in patients with RA was $50 \%$ higher than in the general population, with an increase in coronary disease of $59 \%$ and an increase in cerebrovascular events of $52 \%$ [11]. Quite similar results were obtained in another study by the same authors: $68 \%$ of acute myocardial infarction (MI) and $41 \%$ of strokes [10], which were equivalent to those found in a population without RA but 10 to 15 years older.

CV morbidity and mortality are also increased in AS and PsA [9**,12*]. Several studies have shown an increase in the prevalence of coronary heart disease (CHD), stroke and peripheral arterial disease (PAD) in patients with AS and PsA with respect to the general population $\left[\mathbf{9}^{* *}, \mathbf{1 2} * \mathbf{1 7}\right]$. A meta-analysis confirmed an increase of MI (odds ratio [OR] 1.60; 95\% CI: 1.32-1.93) and stroke (OR 1.50; 95\% CI: 1.39-1.62) in 
patients with AS with respect to the general population [18]. PsA also seems to exhibit similar CV risk, although its estimates are more difficult to determine due to the bias related to the cutaneous involvement of the disease. In a cross-sectional study that compared non-fatal CV events in RA and PsA, the prevalence found was very similar in both entities: $10 \%$ in PsA vs. $12.4 \%$ in RA [19].

Finally, it is important to point out that the clinical manifestations of CVD in patients with IJD, particularly in relation to coronary events, are usually different from the general population. They frequently start with a silent ischemia, often attributed to mechanical pain of the thoracic wall, which frequently causes diagnostic delays of their heart disease and higher mortality [12*].

\subsection{Subclinical atherosclerosis in IJD}

Subclinical CVD in patients with IJD can be detected years before the clinic appears, using different non-invasive methods $[20 *, 21 * *, 22]$. Nowadays, there are several methods available for evaluating subclinical atherosclerosis in these patients (Table 1).

\subsubsection{Assessment of endothelial dysfunction}

Endothelial dysfunction and arterial stiffness are recognized as surrogate measurements of CVD [6,7]. Arterial stiffness can enhance CV risk by increasing atherogenesis or adverse hemodynamic effects. Arterial stiffness is most commonly assessed by aortic pulse wave velocity and augmentation index. Indeed, patients with IJD exhibit increased arterial stiffness [22]. Alternative measures of arterial stiffness include aortic distensibility, and the ankle-brachial elasticity index (ABI), measured using high-sensitivity brachial ultrasonography. Since these methods are laborious and not very sensitive, they are not commonly used in the routine clinical practice. 


\subsubsection{Carotid ultrasound}

Ultrasound (US) is possibly the most simple and useful non-invasive surrogate marker of CVD from a practical point of view. Carotid US provides accurate and reproducible measurements of anatomical structures without harmful ionizing radiation. The two most commonly used measurements by US are the carotid artery intima-media wall thickness (cIMT) and the presence of atheroma plaques into the carotids. Both parameters have shown to be good predictors of $\mathrm{CV}$ events in patients with RA $[\mathbf{2 3}, \mathbf{2 4}]$. Several systematic literature search and meta-analysis have confirmed increased cIMT and greater presence of carotid plaques in patients with RA vs. controls $[25,26 *]$.

Interestingly, US allows reclassifying the $\mathrm{CV}$ risk of IJD patients considered as intermediate or moderate $\mathrm{CV}$ risk through clinical scores in high or very high risk. In fact, an abnormally high incidence of carotid plaques was found in patients with RA that had been categorized as having moderate risk by application of the Systematic COronary Risk Evaluation (SCORE) scale $[27 *$,28]. Similar findings have also been observed in patients with AS and PsA without additional factors of CV risk [29-31]. As observed in RA, patients with AS and PsA also had higher cIMT than matched controls [31-33]. In AS, other abnormal carotid US findings associated with subclinical atherosclerosis, such as higher frequency of plaques than matched controls [32], have also been reported.

Since carotid US is a simple, cheap and reproducible method, it is the most widely used method in the rheumatologic setting. In practical terms, patients with cIMT $\geq 0.9$ $\mathrm{mm}$ are included in the category of high/very high $\mathrm{CV}$ risk $\left[34^{*}, 35\right]$. More interestingly, the presence of carotid plaques reclassifies a patient into the category of very high $\mathrm{CV}$ risk, regardless of the information derived from applying $\mathrm{CV}$ risk charts. 
Moreover, carotid US is a good method to determine progression of atherosclerotic disease in patients with IJD. In these patients the CV risk increases proportionally with the number of plaques and it is greater when plaques are bilateral.

\subsubsection{Computed tomography (CT)}

CT can be used for evaluating the burden of coronary artery calcification (CAC) or for anatomical visualization of coronary arteries by CT coronary angiography (CTCA), being CAC score a good measure of premature atherosclerosis. Both, the American College of Cardiology (ACC) and the European Society of Cardiology (ESC) recommend the use of $\mathrm{CAC}$ score to monitor risk assessment when $\mathrm{CV}$ risk is unclear using traditional CVD risk algorithms $[36,37]$. CAC is also a good predictor of CVE in patients with RA and other autoimmune diseases. Indeed, it was found to be more sensitive than classic risk chart algorithms to identify high-CV risk RA patients [28].

\subsubsection{Positron emission tomography}

Positron emission tomography (PET) myocardial perfusion imaging detects uptake of positron-emitting radiotracers in the heart and perfusion of blood into the myocardium. PET has shown to predict CV mortality in patients with coronary artery disease [38], and it could potentially be applied to the $\mathrm{CV}$ risk stratification of high-risk patient groups such as those with IJD. Limitations of PET include its price, availability of tracers, use of ionizing radiation and limited assessment of cardiac structures [21**].

\subsubsection{Cardiovascular magnetic resonance}

Cardiovascular magnetic resonance $(\mathrm{CMR})$ provides detailed information on the structure and composition of myocardium allowing the detection of a wide variety of myocardial diseases. It is useful for the quantitative evaluation of left and right ventricular volumes, mass and function, cardiac tissue characterization and assessment of thoracic vessels [39]. It can be used for the CV evaluation of patients with IJD and 
autoimmune diseases [39]. The main limitations of CMR include price, its availability and general intrinsic contraindications to magnetic resonance [21**,39]. Chronic myocardial ischemia can be assessed using myocardial perfusion at rest and during pharmacological vasodilator stress $[40 *]$.

Taken all this into account, the ideal imaging technique in the assessment of CVD risk in IJD patients should be cheap, safe, reproducible, able to detect early subclinical disease, predict $\mathrm{CV}$ mortality, identify high- $\mathrm{CV}$ risk patients and assess the specific response to therapies. Although there is no unanimous consensus, we believe that carotid US is currently the best technique to be used in the daily clinical practice (Table 1).

\subsection{Inflammation and atherosclerosis}

Inflammation plays an important role in the pathogenesis of atherosclerosis and CVD both in inflammatory rheumatic diseases $[\mathbf{4 1 - 4 3 * * , 4 4 * * ]}$ and in the general population [45**]. In fact, it contributes to all stages of atherosclerosis, from plaque formation to plaque instability and eventual plaque rupture with its important consequences [43**]. Abnormality of acute phase reactants has been found to be associated with subclinical atherosclerosis and greater CV morbi-mortality in patients with RA [46]. Of note, Creactive protein (CRP) leyel is an independent predictor of CV risk, particularly of MI, in the general population [47]. Notably, higher IL-6 levels are also associated with increased mortality in patients with acute coronary syndromes (ACS) and with increased risk of MI in healthy men $[48,49]$.

Interestingly, chronic inflammation causes an alteration in the lipid profile of patients with IJD. It leads to a reduction of serum total cholesterol (TC), LDL-cholesterol (LDL-C) and HDL-cholesterol (HDL-C) levels. However, this quantitative reduction is associated with a paradoxical increase risk of atherogenesis since HDL-C loses its anti- 
atherogenic properties [50]. Furthermore, lipoprotein (a) $(\mathrm{Lp}(\mathrm{a}))$ is also an important promoter of atherogenesis. When oxidized, it can provoke an immune response similar to that of oxidized LDL, and increases in $\mathrm{Lp}$ (a) levels have been associated with inflammation [51]. Thus, $\mathrm{Lp}(\mathrm{a})$ is an independent risk factor for CVD that may be augmented in RA [51].

To determine if the reduction of the inflammatory burden without affecting lipid levels may reduce the risk of CVD, Ridker et al performed a randomized, double-blind trial of canakinumab, a monoclonal antibody targeting interleukin-1 $\beta$, in a large series of patients with previous myocardial infarction who had high-sensitivity C-reactive protein level $\geq 2 \mathrm{mg} / \mathrm{L}$. Although this biologic agent did not reduce the lipid levels when compared with baseline results, at a median follow-up of 3.7 years, patients treated with canakinumab at a dose of $150 \mathrm{mg}$ subcutaneously every 3 months had a significantly lower rate of recurrent CVE when compared with those receiving placebo [52*]. Interestingly, this effect was independent of any lipid-level lowering. These findings highlight the pivotal effect of inflammation in the development of CVD in the general population. The results also suggest that the blockade of inflammatory pathways may reduce the risk of CVD in the general population. It may also more relevant in patients with IJDs since these individuals have a chronic inflammation status.

A crucial aspect with major clinical relevance in patients with high inflammatory burden is the increased risk of vulnerability and rupture of atherosclerotic plaques $[12 *, 13]$. In a post-mortem study, $48 \%$ of plaques of patients with RA were classified as unstable by histologic criteria compared with $22 \%$ in non-RA controls. Additionally, inflammation in the coronary artery wall was more prominent in subjects with RA than controls [53]. In another study evaluating carotid plaque structure by 
carotid US comparing patients with RA and controls, active RA patients had lower grey-scale plaque values, a typical characteristic of vulnerability and rupture of plaques linked to atherothrombosis $[\mathbf{1 3 , 5 4 * ] .}$

Adipokines are cytokines secreted by adipose tissue. In patients with IJD there is a dysregulated secretion of these molecules due to adipose tissue dysfunction. In fact, it can contribute to the pathogenesis of atherosclerotic disease in this population. In patients with severe RA undergoing anti-TNF-therapy high-grade inflammation negative and independently correlated with circulating adiponectin concentrations whereas low adiponectin levels clustered with metabolic syndrome (MetS) features [55]. Adiponectin levels negatively correlated with triglycerides/HDL-C ratios, TC/HDL-C ratios and high fasting plasma glucose levels, independently of CRP levels and the body mass index (BMI) [55]. Furthermore, a strong association between laboratory markers of inflammation, particularly CRP and resistin levels was found in patients with severe RA undergoing anti-TNF therapy [56]. Also, a positive correlation between BMI and serum level of leptin was found in these patients.

As in RA, inflammation in SpA also plays a pivotal role in all phases of formation and development of atheroma plaques, intensifying the effects of conventional risk factors. An important role of adipokine production in the inflammation and development of atherosclerosis has been found in SpA, particularly in PsA [57]. As previously discussed, an increase in the prevalence of MetS has been documented in patients with IJD [2*], particularly in those with PsA $\left[5^{*}, 59\right]$.

In summary, inflammation has an important contribution to the development of CVD in patients with IJD. Using heart failure (HF) as an example, it has been calculated that classic CVRF explain up to $80 \%$ of the risk of HF in non-RA subjects but only $40 \%$ of 
risk among RA patients, suggesting that mechanisms associated with inflammation are of major importance in these patients $[60 *]$.

\subsection{Traditional $\mathrm{CV}$ risk factors}

Traditional CVRFs, such as smoking, DM, obesity, hypertension (HTN) and dyslipidemia are independently associated with subclinical atherosclerosis, CVE and increased mortality in patients with IJD $[12 *, 61-63]$.

Smoking is known to be a risk factor for the development of RA, particularly in rheumatoid factor $(\mathrm{RF})$ and anti-CCP positive RA patients. A recent meta-analysis showed an increased prevalence of cigarette smoking in patients with RA (OR 1.56, 95\% CI 1.34, 1.80) [64]. Other studies also found a higher prevalence of current and past smokers among patients with RA compared to controls [11].

Although there are contradictory data in the literature, DM appears to be more common in RA patients than in controls. In this regard, insulin resistance (IR) and MetS are increased in patients with PsA and RA $\left[\mathbf{5 8}^{*}, \mathbf{5 9}, \mathbf{6 5}\right]$. Interestingly, some antirheumatic medications such as some anti-tumor necrosis factor (TNF)- $\alpha$ monoclonal antibodies and anti-interleukin (IL)-6 tocilizumab exert a positive effect on IR in patients with RA and AS [66,67]. Likewise, hydroxychloroquine (HCQ), and methotrexate (MTX) may also reduce the risk of DM in RA patients.

Obesity itself contributes to a low-grade inflammation status, as adipose tissue is a major organ producer of pro-inflammatory cytokines. A high BMI is associated with elevated CRP levels and increased risk of CVD in the general population [68]. Abnormal body fat composition in RA and PsA is also associated with higher CRP levels and more severe disease [69]. However, severe and advanced disease in patients with RA is associated with sustained elevation of acute phase reactants and weight 
loss, leading in extreme cases to a state of cachexia which also causes an increased risk CV.

HTN has frequently been found in patients with RA. Whereas some studies highlight HTN as an important risk factor for CVD in RA patients $[6 \mathbf{6 1 , 6 2 , 7 0 ]}$, others found similar prevalence of HTN in RA and in controls [71]. Nevertheless, HTN is frequently underdiagnosed in young people with IJD or undertreated in elderly patients [72]. In AS and PsA, HTN was found in $26 \%$ and $29.5 \%$ of patients, respectively [15]. The issue of lipids deserves a separate mention as independent CV risk factor in IJD. As already mentioned, and although the levels of total CT, LDL and HDL-C decrease during active phases of disease, the CV risk continues increasing $[12 *, 73 *]$. Since in patients with active disease the decrease in the HDL-C fraction is more marked, it is advisable to assess the CT/HDL-C ratio or "atherogenic index" (AI) instead of CT. In this regard, the most adequate time to evaluate the lipid profile in patients with IJD is when the disease is in remission or with low activity since CT levels increase in the phases of inactivity or under the effects of treatment. Lipid abnormalities are also common in PsA with lower serum levels of HDL-C and higher serum levels of triglycerides [57,74]. Dyslipidemia is more prominent in PsA patients with active disease, suggesting a link between inflammation and the lipid profile [74,75]. Low total CT levels have also been reported in AS [76]. As with HTN, dyslipidemia is underdiagnosed and often undertreated in patients with IJD, which can worsen the course and prognosis of this comorbidity $[\mathbf{7 7 , 7 8}]$.

Finally, it is important to remark that the effect of traditional CVRF on the vascular tree may be more harmful in patients with IJD than in the general population, because classic CV risk factors amplify the harmful effect that chronic inflammation produces on the wall of the arteries $[\mathbf{1 2} * \mathbf{1 3}, \mathbf{1 4}]$. 


\subsection{Genetics as a contributor to CV risk in IJD}

Genetics, together with inflammation and traditional CVRF, constitutes the third basic component associated with an increased CV risk in patients with IJD (Figure 1). Family history of premature CVE in a first-degree relative -before 55 years in men and before 65 years in women- raises significantly the risk of CVD in inflammatory patients and in the general population [79*].

There are a number of genetic studies on CVD in patients with IJD, particularly in patients with RA. Among them, the most interesting data regarding CVD risk are found in the genes of the human leukocyte antigen (HLA) region in patients with RA. HLA is also the main genetic factor implicated in inflammatory immune-mediated pathologies and it is associated with more diseases than any other region of the human genome $[80 *]$.

Other genetic polymorphisms of genes implicated in different inflammatory and metabolic pathways, located inside and outside the HLA region, appears to increase the augmented risk of CVD in patients with RA [81-85].

\subsection{Anxiety, depression, renal failure and other emergent $C V$ risk factors (Table 2)}

Anxiety and depression are well known factors associated with CV risk, although sparsely weighted in the current guidelines and CV risk scales. Recent meta-analyses proved that both depression and anxiety are independently associated with incident CVE rates [86,87]. Anxiety can increase CVD risk through decreased adherence to healthy behaviors as well as physiological mechanisms including autonomic dysfunction, inflammation, endothelial dysfunction and increased platelet aggregation [88**]. The prevalence of depression and anxiety is increased in RA patients from high income countries $[\mathbf{8 9 , 9 0 ]}$. They also predict long-term physical health outcomes and treatment response in RA [91]. In this line, the presence of negative feelings 
(anger, hostility, type D personality, etc.), especially when persistent, are associated with an increase in CVD and mortality [92**]. On the other hand, low socioeconomic class individuals, lack of social support, stress at work and/or family life have a negative influence on patients with known CVD [93**] (Table 2).

The link between periodontal disease and CVD in the general population is also wellrecognized. Although the cause-effect relationship is not well understood, there is a suspicion that periodontal bacteria may play a pathogenic role in CVD [94*]. Chronic kidney disease (CKD) was associated with myocardial infarction and fatal coronary heart disease in black, but not in white Americans [95]. Even mildly reduced estimated glomerular filtration rate increases the risk of incident atherosclerotic CVD [96]. Moreover, RA enhances the incidence of CKD. In a cohort study of African RA patients, the estimated glomerular filtration rate (CKD-EPI eGFR) was lower than 90 $\mathrm{ml} / \mathrm{min} / 1.73 \mathrm{~m}^{2}$ in $49.1 \%$ of blacks and $30.6 \%$ of white participants, respectively [97]. Using receiver operator characteristic (ROC) curve analysis, the CKD-EPI eGFR predicted the presence of carotid artery plaque among black RA patients [97]. In fact, a CKD-EPI eGFR lower than $82 \mathrm{ml} / \mathrm{min} / 1.73 \mathrm{~m} 2$ was associated with a 2.22-fold increased prevalence of carotid plaque in black African RA patients [97]. In consequence, in patients with IJD, periodic monitoring of microalbuminuria and proteinuria are recommended because they may help to quantify the organ damage degree secondary to vascular injury.

Low levels of vitamin D have been found in several cohorts of patients with different IJD [98,99]. Several studies have demonstrated the beneficial effect of vitamin D in the control of HTN and CV risk and low levels of vitamin D have been associated with greater CV morbidity [100].

\subsection{Effect of anti-rheumatic medication on CV disease risk}


The use of non-steroidal anti-inflammatory drugs (NSAIDs), including coxibs, has been associated with an increased risk of CV mortality [101]. Nevertheless, a longitudinal cohort study of 17,320 patients with RA followed-up for 5-years average showed a modest increase of CV risk, smaller than that observed in the general population [102]. Whereas NSAIDs exposure was associated with a $22 \%$ of risk increase in patients with RA, the risk following NSAIDs exposure was around $50 \%$ in non-RA patients [102]. A possible explanation for this finding might be related to the beneficial effect that NSAIDs confer on the mobility, which would counteract its direct harmful effect on the CV system. However, it seems prudent to minimize their use, especially in patients with a high CV risk and HTN associated.

We must take special attention to the combined use of NSAIDs and aspirin due to the increased risk of gastrointestinal complications. Besides, some NSAIDs appear to attenuate the antiplatelet effects of aspirin. However, coxibs do not seem to interact with the anti-platelet effects of aspirin. Thus, when a combination of NSAIDs and aspirin is necessary, celexocib -a coxib with a relatively low CV toxicity- might be a reasonable alternative.

Glucocorticoids (GC) exhibit a complex effect on the vascular system. While shortterm at low doses GC do not appear to be harmful and even may be beneficial for the vasculature due to the reduction in inflammation and the improvement in patient mobility, high doses of GC, especially when maintained for long-term, can promote atherosclerosis and increase CV risk.

In a study of 50,238 person-years in 8,384 RA patients, including 298 cases with MI, current use of GCs was associated with a $68 \%$ increased risk of MI in multivariable model. Current daily dose, cumulative duration and total cumulative dose of GC were 
all associated with a significant increased risk of MI [103]. By contrast, GC use was not associated with an increased risk of CVE in another study [104].

There is a general agreement on the fact that both synthetic DMARDs and biologic therapies aimed to reduce and control disease activity can attenuate atherosclerosis by reducing the systemic inflammatory burden. In fact, available data indicate that antiTNF, MTX and HCQ may reduce the CV risk [105,106]. The potential beneficial effect on CVD of other biological therapies is less known. Nonetheless, adequate control of disease activity would reduce the need of using NSAIDs and GC, which would eventually help reduce the incidence of new CVE in these patients.

\subsection{Stratification of CV risk in patients with inflammatory joint diseases}

In order to identify subjects at risk of developing CVE, it is critical to carry out an adequate stratification of the CV risk of patients with IJD. This was classically performed by using scales or risk chart algorithms $\left[21^{* *}, 79 *, 107 *\right]$. Currently, there are several scales available that are extrapolated from those designed for the general population. The best known are the SCORE, the Framingham, the Reynolds Index and the QRISK2. In Europe, the most widely used and supported by the ESC is the SCORE, which calculates the risk of fatal coronary events at 10 years and stratifies the risk as low $(<1 \%)$, moderate $(\geq 1 \%$ and $<5 \%)$, high $(\geq 5 \%$ and $<10 \%)$ and very high $(\geq$ $10 \%$ ) (Table 3). In addition, SCORE classifies patients as they come from countries with high or low CV risk. The QRISK2 is the scale most commonly used in the United Kingdom, while the Framingham Index (Framingham Risk Score or FRS) is the algorithm most commonly used in the USA and Canada. Unlike SCORE, it assesses the risk of fatal and non-fatal coronary events also at 10 years and classifies patients as having low (risk $<10 \%$ ), intermediate $(\geq 10$ and $<20 \%)$ and high $(\geq 20 \%)$ risk (Table $3)$. 
Several pieces of evidence indicate that these algorithms underestimate (Framingham, Reynolds and SCORE) or overestimate (QRISK2) the actual CV risk in patients with RA [21**,107*]. For this reason, a new scale, the expanded risk score for RA (ERSRA), has been developed using data from the CORONA register [108*]. This scale incorporates specific risk factors for RA. However, the ERS-RA has also a trend to reclassify patients below the actual $\mathrm{CV}$ risk value [21**]. The application of these scales to other IJD is not validated yet, so their usefulness in other diseases cannot be estimated.

The EULAR task force proposed a modified SCORE system as a mean of improving $\mathrm{CV}$ risk stratification [109**]. It is obtained by using a multiplication factor of 1.5 applied to the calculated SCORE risk in patients with RA.. The updated 2015/2016 EULAR recommendations indicate that this 1.5 multiplier factor must be applied to all patients with RA (other indexes such as QRISK2 multiply by 1.4) irrespective of other risk factors, and even then, we may fall short of the actual CV risk estimation of our patients with IJD [110]. However, this CVD risk calculator has not been prospectively evaluated in patients with RA so that its validity has not yet proven [111**].

For this reason, other recommendations such as the Dutch multidisciplinary guidelines for the management of $\mathrm{CV}$ risk advise to increase systematically the age of the patient with RA by 10-15 years to calculate their CV risk more accurately [112]. Although the same could apply to AS and PsA, we do not have sufficient evidence today to extend the same correction factor to these two pathologies.

The use of non-invasive imaging techniques such as carotid US enables us to classify and stratify more adequately the CV risk of patients with IJD. This is especially true for intermediate risk patients. Thus, an increased cIMT $>0.90 \mathrm{~mm}$ or the presence of unilateral or bilateral carotid atheroma plaques detected by US allowed reclassifying at 
high or very high risk up to $63 \%$ of patients with RA previously classified as moderate risk by indexes [27**]. Recently, the same has been demonstrated in patients with AS [29]. In keeping with that, in a series of 226 patients with PsA, Eder et al. observed that

$56.1 \%$ of the patients in the FRS-based low to intermediate risk groups had carotid plaques. Interestingly, $55.9 \%$ of the patients from the FRS-based intermediate risk category were reclassified into an US-based high-risk category, while $47.1 \%$ of the patients in the FRS-based low-risk category were reclassified into a higher US-based risk group [113].

Another scale of great clinical interest is the one proposed by the ACC/AHA for lipidlowering treatment (LLT), in which 3 main risk categories are considered: low risk $(<5 \%)$, intermediate risk $(\geq 5$ and $<7.5 \%)$ and high risk $(\geq 7.5 \%$ and/or age between 40 and 75 years plus DM and/or LDL-C $>4.9$ mmol/L and/or established CVD) [114**]. According to these guidelines, treatment is recommended for all high-risk patients, but not advised for low-risk patients, and it should be considered individually for intermediate-risk patients $[79 *, 114 * *]$.

All the data mentioned have a direct impact on the treatment of patients with IJD. Strictly applying CV management recommendations will prevent CVE more appropriately and reduce mortality in these patients (Table 3).

\subsection{Prevention and treatment of cardiovascular disease in IJD}

Based on the aforementioned risk scales, particularly on the SCORE, the European League Against Rheumatism (EULAR) updated in 2016 the recommendations for CV risk management in patients with IJD. Although these recommendations are initially focused on RA, due to the increasing scientific evidence available, they can also be applied to other IJD [111**]. 
Furthermore, the EULAR task force emphasizes the relevant role of the rheumatologists in this strategy. Indeed, rheumatologists should coordinate the overall treatment strategy of $\mathrm{CV}$ morbidity promoting healthy lifestyle habits, such as a cardioprotective diet, sodium restriction, regular physical exercise, adequate sun exposure, weight control, avoiding overweight and insisting on toxic habits cessation, especially smoking $[111 * *, 115,116 * *, 117,118]$.

Interestingly, due to the negative effect of vitamin D deficiency on the CV system, an optimal intake of vitamin D and omega-3 acids (primarily from the diet) should be guaranteed. Besides other beneficial effects, omega-3 acids are likely to reduce CV risk and RA symptoms due multiple functions, including an anti-inflammatory and NSAIDs sparing effect $[\mathbf{1 1 9 , 1 2 0}]$. Moderate physical activity is advisable, preferably aerobic, at least 2.5-5 hours per week, ideally performing at least 30 min daily. Since many patients will have functional sequelae due to their underlying disease, special exercise programs directed by physiotherapists are suggested.

It is also important to keep in mind that intensive dental hygiene appears to reduce the $\mathrm{CV}$ risk in general population [121-122]. However, the effects of dental hygiene on CV morbidity in IJDs deserves further studies.

It is important to limit the use of potentially cardiotoxic medication, such as NSAIDs and GC $[111 * *, 115]$. Although NSAIDs may have a lesser harmful effect in IJD than in the general population, due to their potential anti-inflammatory effects along with other potential beneficial effects in these patients such as the improvement of mobility, they should be used at the lowest dose and for the shortest possible time $[111 * *, 123 *, 124]$. Regarding GC, they should also be used with caution, at the lowest dose and for the shortest possible period of time, due to its harmful effect on the vascular system, especially at high and maintained doses $[111 * *, 123 *]$. Other 
medications such as leflunomide and cyclosporine A should be used with caution, especially in HTN patients with IJD [125].

Control of disease activity is a key objective as it has been associated with a reduction of CV mortality in patients with IJD. RA patients in remission have lower levels of inflammation biomarkers, lower blood pressure (BP) and better arterial compliance [126]. Among DMARDs, MTX use has been associated with reductions in CVD in several studies [127]. This evidence was stronger for the overall reduction in CV morbidity and mortality but weaker for stroke reduction [127].

TNF- $\alpha$ inhibitors may protect against $C V$ events in patients with RA, as shown in a meta-analysis of 16 cohort studies, in which the risk reductions associated with TNF- $\alpha$ blockers use were $31 \%$ for any CVE, $19 \%$ for MI and $15 \%$ for stroke [106]. The CORRONA registry, including 10,156 RA patients followed-up for a mean of 22.9 months, supported this beneficial role as the risk of CVE (MI, stroke, and death) in the subgroup on TNF- $\alpha$ antagonists was lower than in the subgroup receiving MTX or other DMARDs [128]. Significant risk reductions were also found for nonfatal MI or stroke [128].

Regarding HTN, there are no specific recommendations different from those used in the general population. Currently, and according to the recommendations by the ESC, it is advisable to maintain systolic BP (SBP) figures $<140 \mathrm{~mm} \mathrm{Hg}$ and diastolic BP (DBP) $<90 \mathrm{~mm} \mathrm{Hg}$, as in the general population [92**,129**]. According to the 2017 American HTN Guidelines [130**], the use of antihypertensive agents for primary intervention is recommended in patients with $\mathrm{SBP} \geq 130 \mathrm{mmHg}$ or $\mathrm{DBP} \geq 80 \mathrm{mmHg}$ who have increased overall atherosclerotic CVD risk, whereas the cut points are SBP> $140 \mathrm{mmHg}$ or DBP>90 mmHg in patients without increased CV risk [130**]. 
Therefore, tight control of BP is recommended in patients with IJD. In fact, BP values $<130 / 80 \mathrm{mmHg}$ should be desirable in these patients.

With respect to dyslipidemia, diet modification is the first step for its management. When this measure is unsatisfactory, lipid lowering agents should be added. Among them, statins represent the first line of therapy $[116 * *, 131 * *] . ~ O v e r a l l$, statins induce a major decrease in CVE risk. According to a meta-analysis of 26 randomized controlled trials on statins, a reduction of $40 \mathrm{mg} / \mathrm{dL}$ in LDL-C levels is associated with $20 \%$ decrease in CVE and a $10 \%$ decrease in mortality [132*]. In secondary prevention, the LDL-C reduction with statins and MI recurrence rate were not different between patients with or without IJD [133].

According to the guidelines of the ESC, different risk categories and a series of target levels have been established [92**]. In subjects with moderate CV risk (SCORE level $\geq 1$ to $<5 \%$ ), they recommend achieving $\mathrm{LDL}-\mathrm{C}<115 \mathrm{mg} / \mathrm{dL}(3 \mathrm{mmol} / \mathrm{L})$. In those at high $\mathrm{CV}$ risk (SCORE level $\geq 5$ to $<10 \%$ ), a LDL-C goal $<100 \mathrm{mg} / \mathrm{dL}(2.6 \mathrm{mmol} / \mathrm{L})$ is recommended. Finally, in patients at very high CVD risk (SCORE $\geq 10 \%$ ), the recommended LDL target is $<70 \mathrm{mg} / \mathrm{dL}(1.8 \mathrm{mmol} / \mathrm{L})$ or a $\geq 50 \%$ reduction in $\mathrm{LDL}-\mathrm{C}$ levels versus baseline levels when the therapeutic goal cannot be reached [92**].

Nevertheless, these criteria have been much more stringent in the last ESC/EAS guidelines for the management of dyslipidemias of 2019 published online at the end of August this year $\left[\mathbf{1 3 4}^{* *}\right]$. These guidelines established the following therapeutic objectives: 1) An LDL-C reduction $\geq 50 \%$ from baseline and an LDL-C goal $<1.4$ $\mathrm{mmol} / \mathrm{L}(<55 \mathrm{mg} / \mathrm{dL})$ from baseline for secondary prevention and for primary prevention in patients at very-high risk. 2) An LDL-C goal $<1.0 \mathrm{mmol} / \mathrm{L}(<40 \mathrm{mg} / \mathrm{dL})$ for patients with atherosclerotic CVD who experience a second vascular event within 2 years (not necessarily of the same type as the first event) while taking maximally 
tolerated statin-based therapy. 3) An LDL-C reduction $\geq 50 \%$ from baseline and an LDL-C goal $<1.8 \mathrm{mmol} / \mathrm{L}(<70 \mathrm{mg} / \mathrm{dL})$ in patients at high risk. 4) An LDL-C goal $<2.6 \mathrm{mmol} / \mathrm{L}(<100 \mathrm{mg} / \mathrm{dL})$ in individuals at moderate risk, and an LDL-C goal $<3.0$ $\mathrm{mmol} / \mathrm{L}(<116 \mathrm{mg} / \mathrm{dL})$ in individuals at low CV risk $[134 * *, 135]$.

Despite their proved efficacy and remarkable safety, statins are not always sufficient to reach recommended LDL-C targets in individual patients. Based on findings in the general population, we recommend using ezetimibe in IJD patients when the LDL-C target is not reached despite maximally tolerated statin doses. Furthermore, in intolerant or refractory patients with high/very high $\mathrm{CV}$ risk, a proprotein convertase subtilisin/kexin 9 (PCSK9) inhibitor should be added, although the experience with PCSK9 inhibitors in IJDs is still limited. This should be viewed in light of recently reported investigations including the ODYSSEY Outcomes trial [136*].

IJD patients with moderate $\mathrm{CV}$ risk according to risk chart algorithms that are reclassified as having very high CV risk by a non-invasive technique (e.g., presence of plaques in the carotid US), LDL-C target could be similar to that for individuals with very high $\mathrm{CV}$ risk or SCORE $\geq 10 \%$ [137]. Regarding HDL-C, there is not enough scientific evidence for any figure to be considered as a therapeutic goal, although HDL-C $<40 \mathrm{mg} / \mathrm{dL}(<1.0 \mathrm{mmol} / \mathrm{L})$ in men and $<45 \mathrm{mg} / \mathrm{dL}(<1.2 \mathrm{mmol} / \mathrm{L})$ in women indicates high CV risk [92**].

Due to the reduction of TC and cholesterol fractions levels detected during the phases of activity in patients with IJD, it is generally advised to measure lipid levels when the patient is in a stable/inactive phase. Likewise, according to the latest EULAR recommendations $\left[\mathbf{1 1 1}^{* *}\right.$ ], it is advisable to evaluate $\mathrm{CV}$ risk in patients with IJD at least once every 5 years in low-risk patients (in the previous guideline, the control was advised to be done annually). In those with intermediate or high risk, it is advisable to 
do it more frequently, even on an annual basis, especially if there is evidence of progression of underlying disease or important changes in the treatment.

The recommendations for the use of low dose aspirin in IJD patients must follow those proposed for the general population. In this way, low dose aspirin has only been recommended in patients with established CVD $[\mathbf{9 2} * *, 131 * *]$.

Regarding vaccination, influenza epidemics are associated with an increased rate of CVE, and influenza vaccination in the general population appears to be a cost-effective CV prevention modality. This effect is probably greatest in high risk groups [138]. The European guidelines on CVD prevention in clinical practice recommended influenza vaccination in secondary CV prevention [139]. Similarly, the CV risk may also be reduced by pneumococcal vaccination [140]. Because IJD patients are at increased risk of infections due to immune dysregulation and immunosuppressive treatment, appropriate vaccination should be addressed, especially in high CV risk patients.

As it has been exposed in this section, most studies and recommendations discussed in this section are focused on RA. Although they cannot be generalized to other IJDs, it seems to be reasonable to think that some of them may be extrapolated to AS and PsA until we have specific data on every one of these entities.

\subsection{Conclusions}

Cardiovascular disease is a frequent cause of morbidity and mortality in IJDs. The increase of this comorbidity is determined by classic CV risk factors linked to the underlying disease and the persistence of inflammation in a host with a specific genetic component. The development of CVE can occur early in the course of disease or after years of subclinical disease. Since CVD is associated with high mortality, it is important to stratify the CV risk adequately to identify individuals at high risk of CVE before symptoms appear. More importantly, current recommendations for primary and 
secondary prevention of CVE should be strictly followed to prevent the occurrence of new events and reduce $\mathrm{CV}$ mortality.

\section{Expert opinion}

Cardiovascular disease is a common cause of morbi-mortality in IJDs. The increase of this comorbidity is determined by traditional CVRF, genetic factors, and other factors dependent on the specific underlying disease. It should be noted that some of the traditional risk factors, such as HTN, dyslipidemia or diabetes can remain unnoticed for many years in these patients. There are also other less known emergent CVRF that are more difficult to evaluate. Clinical manifestations in these patients are often atypical and can be misdiagnosed, in the case of ACS, with musculoskeletal pain which often causes delayed diagnosis which may aggravate the prognosis and increase the mortality. Currently, some imaging techniques enable us to visualize the lesions anatomically and to establish a CV risk assessment early in the course of disease. Among them, carotid-US (cUS) is the simplest, cheapest, most reliable and reproducible available method at this moment. US has a high sensitivity and specificity, and an excellent association with CVE development, especially at coronary and/or cerebrovascular level.

There are several scales to assess the CV risk for a specific patient. In Europe, the most commonly used risk algorithm is the modified SCORE according to the recommendations proposed by the EULAR task force [111**], which enables us to classify patients as low, moderate, high or very-high risk and apply different preventive measures according to the specific risk obtained. However, the calculation of risk through the application of these scales in some patients is far from reality, needing the help of complementary imaging techniques. In this way, it is possible to reclassify and stratify patients more appropriately. Thus, intermediate/moderate CV 
risk patients with increased cIMT or presence of carotid plaques on US should be considered as having high/very high risk and should be treated consequently. With respect to this, by using carotid US it has been possible to reclassify more than $50 \%$ of patients of intermediate or moderate risk as high or very high-risk patients [27**]. Treatment of high CV risk patients must be multidisciplinary. However, we are aware of the lower adherence to cardioprotective therapy of these patients $[\mathbf{7 2 , 7 7 , 7 8 ]}$. For this reason, it is important to remark that both physicians and patients should be concerned about the increased risk of $\mathrm{CVE}$, sometimes fatal, in these population. An additional measure to be performed in the follow-up of these subjects is the periodical assessment of renal damage by quantifying microalbuminuria and proteinuria as the result of atherosclerotic organ damage.

Here, it is important to reinforce positively basic recommendations changing the patient's lifestyle if necessary, advising healthy cardioprotective measures and frequent aerobic exercise adapted to every individual, avoiding toxic habits such as tobacco and alcohol. We must stimulate the patient to observe all the general recommendations and pharmacological measures established in the clinical guidelines with the final goal to reach the more suitable therapeutic objective individualized to every patient.

Unfortunately, there are still many unmet needs in this field, as it is reflected in Table 4 , but it is essential to take into account that early diagnosis and management of the subclinical atherosclerotic disease must be a key part in the context of the routine clinical practice in coming years incorporating to the management imaging techniques. Therefore, overall CV risk assessment must be the ultimate goal to reduce the risk of CVD in patients with IJD. 


\section{Acknowledgements}

We thank Drs. Carmen Suárez and Iluminada García-Polo, from HTN Unit (Department of Internal Medicine) of the Hospital de La Princesa (Madrid) for their positive ideas and constructive remarks to our manuscript.

\section{Funding}

MA González-Gay's research has been supported by grants from "Fondo de Investigaciones Sanitarias" PI06/0024, PS09/00748, PI12/00060, PI15/00525, PI18/00043, and RD12/0009/0013 and RD16/0012 (RIER) from "Instituto de Salud Carlos III" (ISCIII) (Spain), co-funded by FEDER funds.

\section{Declaration of interest}

$S$ Castañeda has received trip aids for Congresses and grants from Abbvie, Amgen, BMS, LILLY, Janssen, MSD, Pfizer, Roche, Sanofi and UCB, and Advisory Board consultation fees from Amgen, LILLY, MSD, Pfizer, Roche and Sanofi. MAGonzalezGay has received grants/research supports from Abbott, MSD and Roche, and had consultation fees/participation in company sponsored speaker's bureau from Abbott, Celgene, Pfizer, Roche, Sanofi and MSD. The authors have no other relevant affiliations or financial involvement with any organization or entity with a financial interest in or financial conflict with the subject matter or materials discussed in the manuscript apart from those disclosed.

\section{Reviewer disclosures}

Peer reviewers on this manuscript have no relevant financial or other relationships to disclose.

\section{References}


Papers of special note have been highlighted as either of interest (•) or of considerable interest $(\bullet)$ to readers.

1. Gullick NJ, Scott DL. Co-morbidities in established rheumatoid arthritis. Best Pract Res Clin Rheumatol. 2011;25:469-483.

*2. Kerekes G, Nurmohamed MT, González-Gay MA, et al. Rheumatoid arthritis and metabolic syndrome. Nat Rev Rheumatol. 2014;10:691-696.

*Interesting review about the complex relationship between metabolic syndrome and rheumatoid arthritis.

3. van der Horst-Bruinsma IE, Nurmohamed MT, Landewé RB. Comorbidities in patients with spondyloarthritis. Rheum Dis Clin North Am. 2012;38:523-538.

4. Husni ME. Comorbidities in Psoriatic Arthritis. Rheum Dis Clin North Am. 2015;41:677-698.

*5. Scott DL, Wolfe F, Huizinga TW. Rheumatoid arthritis. Lancet 2010;376(9746):1094-1108.

*Classic and complete review on rheumatoid arthritis.

6. Gonzalez-Gay MA, Gonzalez-Juanatey C, Martin J. Rheumatoid arthritis: a disease associated with accelerated atherogenesis. Semin Arthritis Rheum. 2005;35:8-17.

7. Kitas GD, Gabriel SE. Cardiovascular disease in rheumatoid arthritis: state of the art and future perspectives. Ann Rheum Dis. 2011;70:8-14.

8. Ramonda R, Lo Nigro A, Modesti V, et al. Atherosclerosis in psoriatic arthritis. Autoimmun Rev. 2011;10:773-778. 
**9. Agca R, Heslinga SC, van Halm VP, Nurmohamed MT. Atherosclerotic cardiovascular disease in patients with chronic inflammatory joint disorders. Heart. 2016;102:790-795

**Interesting update on atherosclerotic disease in patients with chronic inflammatory joint disorders.

10. Avina-Zubieta JA, Thomas J, Sadatsafavi M, et al. Risk of incident cardiovascular events in patients with rheumatoid arthritis: a meta-analysis of observational studies. Ann Rheum Dis. 2012;71:1524-1529.

11. Aviña-Zubieta JA, Choi HK, Sadatsafavi M, et al. Risk of cardiovascular mortality in patients with rheumatoid arthritis: a meta-analysis of observational studies. Arthritis Rheum. 2008;59:1690-1697.

*12. Castañeda S, Nurmohamed MT, González-Gay MA. Cardiovascular disease in inflammatory rheumatic diseases. Best Pract Res Clin Rheumatol. 2016;30:851-869. * Recent review on cardiovascular morbidity in inflammatory rheumatic diseases. 13. Castañeda S, González-Juanatey C, González-Gay MA. Sex and Cardiovascular Involvement in Inflammatory Joint Diseases. Clin Rev Allergy Immunol. 2019;56:278292.

14. Castañeda S, Gonzalez-Juanatey C, Gonzalez-Gay MA. Inflammatory Arthritis and Heart Disease. Curr Pharm Des. 2018;24:262-280.

15. Castañeda S, Martín-Martínez MA, González-Juanatey C, et al; CARMA Project Collaborative Group. Cardiovascular morbidity and associated risk factors in Spanish patients with chronic inflammatory rheumatic diseases attending rheumatology clinics: Baseline data of the CARMA Project. Semin Arthritis Rheum. 2015;44:618-626. 
16. Van den Hoek J, Roorda LD, Boshuizen HC, et al. Trend in and predictors for cardiovascular mortality in patients with rheumatoid arthritis over a period of 15 years: a prospective cohort study. Clin Exp Rheumatol. 2016;34:813-819.

17. Szabo SM, Levy AR, Rao SR, et al. Increased risk of cardiovascular and cerebrovascular diseases in individuals with ankylosing spondylitis: a population-based study. Arthritis Rheum. 2011;63:3294-3304.

18. Mathieu S, Pereira B, Soubrier M. Cardiovascular events in ankylosing spondylitis: an updated meta-analysis. Semin Arthritis Rheum. 2015;44:551-555.

19. Jamnitski A, Visman IM, Peters MJ, Boers M, Dijkmans BA, Nurmohamed MT. Prevalence of cardiovascular diseases in psoriatic arthritis resembles that of rheumatoid arthritis. Ann Rheum Dis. 2011;70:875-876.

*20. Kerekes G, Soltész P, Nurmohamed MT, et al. Validated methods for assessment of subclinical atherosclerosis in rheumatology. Nat Rev Rheumatol. 2012;8:224-234.

*Overview of validated techniques currently available to determine subclinical atherosclerosis in patients with rheumatic conditions.

**21. Fent GJ, Greenwood JP, Plein S, Buch MH. The role of non-invasive cardiovascular imaging in the assessment of cardiovascular risk in rheumatoid arthritis: where we are and where we need to be. Ann Rheum Dis. 2017;76:1169-1175.

**Exciting and recent review on non-invasive cardiovascular imaging in the assessment of cardiovascular risk in rheumatoid arthritis.

22. Robustillo-Villarino M, Alegre-Sancho JJ, Rodilla-Sala E, et al. Pulse wave velocity and augmentation index are not independently associated with carotid atherosclerosis in patients with rheumatoid arthritis. Clin Rheumatol. 2017;36:2601-2606. 
23. Gonzalez-Juanatey C, Llorca J, Martin J, Gonzalez-Gay MA. Carotid intima-media thickness predicts the development of cardiovascular events in patients with rheumatoid arthritis. Semin Arthritis Rheum. 2009;38:366-371.

24. Evans MR, Escalante A, Battafarano DF, et al. Carotid atherosclerosis predicts incident acute coronary syndromes in rheumatoid arthritis. Arthritis Rheum. 2011;63:1211-1220.

25. van Sijl AM, Peters MJ, Knol DK, et al. Carotid intima media thickness in rheumatoid arthritis as compared to control subjects: a meta-analysis. Semin Arthritis Rheum. 2011;40:389-397.

*26. Ambrosino P, Lupoli R, Di Minno A, et al. Subclinical atherosclerosis in patients with rheumatoid arthritis. A meta-analysis of literature studies. Thromb Haemost. 2015;113:916-930.

\section{*Meta-analysis about subclinical atherosclerosis in patients with RA.}

**27. Corrales A, González-Juanatey C, Peiró ME, et al. Carotid ultrasound is useful for the cardiovascular risk stratification of patients with rheumatoid arthritis: results of a population-based study. Ann Rheum Dis. 2014;73:722-727.

**Original and well-designed study about stratification of patients with rheumatoid arthritis through carotid ultrasound.

28. Corrales A, Parra JA, González-Juanatey C, et al. Cardiovascular risk stratification in rheumatic diseases: carotid ultrasound is more sensitive than Coronary Artery

Calcification Score to detect subclinical atherosclerosis in patients with rheumatoid arthritis. Ann Rheum Dis. 2013;72:1764-1770.

29. Rueda-Gotor J, Llorca J, Corrales A, et al. Carotid ultrasound in the cardiovascular risk stratification of patients with ankylosing spondylitis: results of a population-based study. Clin Exp Rheumatol. 2016;34:885-892. 
30. Rueda-Gotor J, Llorca J, Corrales A, et al. Cardiovascular risk stratification in axial spondyloarthritis: carotid ultrasound is more sensitive than coronary artery calcification score to detect high-cardiovascular risk axial spondyloarthritis patients. Clin Exp Rheumatol. 2018;36:73-80.

31. Gonzalez-Juanatey C, Llorca J, Amigo-Diaz E, et al. High prevalence of subclinical atherosclerosis in psoriatic arthritis patients without clinically evident cardiovascular disease or classic atherosclerosis risk factors. Arthritis Rheum. 2007;57:1074-1080.

32. Gonzalez-Juanatey C, Vazquez-Rodriguez TR, Miranda-Filloy JA, et al. The high prevalence of subclinical atherosclerosis in patients with ankylosing spondylitis without clinically evident cardiovascular disease. Medicine (Baltimore). 2009;88:358-365.

33. Di Minno MN, Iervolino S, Peluso R, et al; CaRRDs study group. Carotid intimamedia thickness in psoriatic arthritis: differences between tumor necrosis factor- $\alpha$ blockers and traditional disease-modifying antirheumatic drugs. Arterioscler Thromb Vasc Biol. 2011;31:705-712.

*34. González-Gay MA, González-Juanatey C, Llorca J. Carotid ultrasound in the cardiovascular risk stratification of patients with rheumatoid arthritis: when and for whom? Ann Rheum Dis. 2012;71:796-798.

*Provocative viewpoint on carotid ultrasound usefulness in the cardiovascular risk stratification of patients with rheumatoid arthritis.

35. Naqvi TZ, Lee MS. Carotid intima-media thickness and plaque in cardiovascular risk assessment. JACC Cardiovasc Imaging. 2014;7:1025-1038.

36. Goff DC, Lloyd-Jones DM, Bennett G, et al. 2013 ACC/AHA guideline on the assessment of cardiovascular risk: a report of the American college of cardiology/ American heart association task force on practice guidelines. J Am Coll Cardiol. 2014;63:2935-2959. 
37. Montalescot G, Sechtem U, Achenbach S, et al. 2013 ESC guidelines on the management of stable coronary artery disease. Eur Heart J. 2013;34:2949-3003.

38. Murthy VL, Naya M, Foster CR, et al. Improved cardiac risk assessment with noninvasive measures of coronary flow reserve. Circulation. 2011;124:2215-2224.

39. Ripley DP, Motwani M, Plein S, et al. Established and emerging cardiovascular magnetic resonance techniques for the assessment of stable coronary heart disease and acute coronary syndromes. Quant Imaging Med Surg. 2014;4:330-344.

*40. Mavrogeni SI, Kitas GD, Dimitroulas T, et al. Cardiovascular magnetic resonance in rheumatology: Current status and recommendations for use. Int $\mathbf{J}$ Cardiol. 2016;217:135-148.

* Recent overview on application and indications of cardiac magnetic resonance in rheumatology.

41. Gonzalez-Gay MA, Gonzalez-Juanatey C, Lopez-Diaz MJ, et al. HLA-DRB1 and persistent chronic inflammation contribute to cardiovascular events and cardiovascular mortality in patients with rheumatoid arthritis. Arthritis Rheum. 2007;57:125-132.

42. Calder PC, Bosco N, Bourdet-Sicard R, et al. Health relevance of the modification of low grade inflammation in ageing (inflammageing) and the role of nutrition. Ageing Res Rev. 2017;40:95-119.

**43. Libby P. Role of inflammation in atherosclerosis associated with rheumatoid arthritis. Am J Med. 2008;121(Suppl 1):S21-S31.

*Interesting manuscript about the role of inflammation in atherosclerosis.

**44. Crowson CS, Rollefstad S, Ikdahl E, et al. A Trans-Atlantic Cardiovascular Consortium for Rheumatoid Arthritis (ATACC-RA). Impact of risk factors associated with cardiovascular outcomes in patients with rheumatoid arthritis. Ann Rheum Dis. 2018;77:48-54. 


\section{**Recent study performed in a large, international cohort of RA patients demonstrating that $30 \%$ of $\mathrm{CV}$ events are attributed specifically to disease characteristics in patients with RA.}

**45. Libby P, Ridker PM, Hansson GK. Progress and challenges in translating the biology of atherosclerosis. Nature. 2011;473:317-325.

\section{** A classic manuscript about the biology of atherosclerosis.}

46. Greenberg JD, Furer V, Farkouh ME. Cardiovascular safety of biologic therapies for the treatment of RA. Nat Rev Rheumatol. 2012;8:13-21.

47. Ridker PM, Buring JE, Shih J, et al. Prospective study of C-reactive protein and the risk of future cardiovascular events among apparently healthy women. Circulation. 1998;98:731-733.

48. Biasucci LM, Liuzzo G, Fantuzzi G, et al. Increasing levels of interleukin (IL)-1Ra and IL-6 during the first 2 days of hospitalization in unstable angina are associated with increased risk of in-hospital coronary events. Circulation. 1999;99:2079-2084. 49. Ridker PM, Rifai N, Stampfer MJ, Hennekens CH. Plasma concentration of interleukin-6 and the risk of future myocardial infarction among apparently healthy men. Circulation. 2000;101:1767-1772.

50. Popa CD, Arts E, Fransen J, van Riel PL. Atherogenic index and high-density lipoproteincholesterol as cardiovascular risk determinants in rheumatoid arthritis: the impact of therapy with biologicals. Mediators Inflamm. 2012;2012:785946.

51. van Breukelen-van der Stoep DF, Klop B, van Zeben D, et al. Cardiovascular risk in rheumatoid arthritis: how to lower the risk? Atherosclerosis. 2013;231:163-172.

*52. Ridker PM, Everett BM, Thuren T, et al; CANTOS Trial Group. Antiinflammatory Therapy with Canakinumab for AtheroscleroticDisease. N Engl J Med. 2017;377:11191131. 
*Recent paper demonstrating the favorable effect of blocking the interleukin-1ß with canakinumab at a dose of $150 \mathrm{mg}$ every 3 months on $\mathrm{CV}$ morbidity in patients with history of MI and CRP increased, independently of lipid-level lowering. 53. Aubry MC, Maradit-Kremers H, Reinalda MS, et al. Differences in atherosclerotic coronary heart disease between subjects with and without rheumatoid arthritis. J Rheumatol. 2007;34:937-942.

*54. Semb AG, Rollefstad S, Provan SA, et al. Carotid plaque characteristics and disease activity in rheumatoid arthritis. J Rheumatol. 2013;40:359-368.

*Important paper that characterizes the differences and vulnerability of carotid plaques by ultrasound in patients with active $R A$ in comparison with inactive RA and non-RA controls.

55. Gonzalez-Gay MA, Llorca J, Garcia-Unzueta MT, et al. High-grade inflammation, circulating adiponectin concentrations and cardiovascular risk factors in severe rheumatoid arthritis. Clin Exp Rheumatol. 2008;26:596-603.

56. Gonzalez-Gay MA, Garcia-Unzueta MT, Gonzalez-Juanatey C, et al. Anti-TNFalpha therapy modulates resistin in patients with rheumatoid arthritis. Clin Exp Rheumatol. 2008;26:311-316.

57. Papagoras C, Voulgari PV, Drosos AA. Atherosclerosis and cardiovascular disease in the spondyloarthritides, particularly ankylosing spondylitis and psoriatic arthritis.

Clin Exp Rheumatol. 2013;31:612-620.

*58. Jamnitski A, Symmons D, Peters MJ, et al. Cardiovascular comorbidities in patients with psoriatic arthritis: a systematic review. Ann Rheum Dis. 2013;72:211-216.

* Reference systematic review on cardiovascular comorbidity in psoriatic arthritis. 
59. Zhang J, Fu L, Shi J, et al. The risk of metabolic syndrome in patients with rheumatoid arthritis: a meta-analysis of observational studies. PloS One. 2013;8:e78151.

*60. Crowson CS, Nicola PJ, Maradit Kremers H, et al. How much of the increased incidence of heart failure in Rheumatoid Arthritis is attributable to traditional cardiovascular risk factors and ischemic heart disease? Arthritis Rheum. 2005;52:30393044.

*Interesting manuscript that help to know the real contribution of traditional CVRFs in the development of heart failure in patients with RA.

61. Liao KP, Solomon DH. Traditional cardiovascular risk factors, inflammation and cardiovascular risk in rheumatoid arthritis. Rheumatology (Oxford). 2013;52:45-52.

62. Sen D, González-Mayda M, Brasington RD Jr. Cardiovascular disease in rheumatoid arthritis. Rheum Dis Clin North Am. 2014;40:27-49.

63. Giles JT. Cardiovascular disease in rheumatoid arthritis: Current perspectives on assessing and mitigating risk in clinical practice. Best Pract Res Clin Rheumatol. 2015;29:597-613.

64. Nurmohamed MT. Cardiovascular risk in rheumatoid arthritis. Autoimmun Rev. 2009;8:663-667.

65. Ferraz-Amaro I, González-Juanatey C, López-Mejias R, Riancho-Zarrabeitia L, González-Gay MA. Metabolic syndrome in rheumatoid arthritis. Mediators Inflamm. 2013;2013:710928.

66. Gonzalez-Gay MA, Gonzalez-Juanatey C, Vazquez-Rodriguez TR, et al. Insulin resistance in rheumatoid arthritis: the impact of the anti-TNF-alpha therapy. Ann N Y Acad Sci. 2010;1193:153-159. 
67. Miranda-Filloy JA, Llorca J, Carnero-López B, et al. TNF-alpha antagonist therapy improves insulin sensitivity in non-diabetic ankylosing spondylitis patients. Clin Exp Rheumatol. 2012;30:850-855.

68. Ridker PM, Buring JE, Rifai N, Cook NR. Development and validation of improved algorithms for the assessment of global cardiovascular risk in women: the Reynolds Risk Score. JAMA 2007;297:611-619.

69. Giles JT, Bartlett SJ, Andersen R, et al. Association of body fat with C-reactive protein in rheumatoid arthritis. Arthritis Rheum. 2008;58:2632-2641.

70. Chung CP, Giles JT, Petri M, et al. Prevalence of traditional modifiable cardiovascular risk factors in patients with rheumatoid arthritis: comparison with control subjects from the multi-ethnic study of atherosclerosis. Semin Arthritis Rheum. 2012;41:535-544.

71. Boyer JF, Gourraud PA, Cantagrel A, et al. Traditional cardiovascular risk factors in rheumatoid arthritis: a meta-analysis. Joint Bone Spine. 2011;78:179-183.

72. van Breukelen-van der Stoep DF, van Zeben D, Klop B, van de Geijn GJ, Janssen HJ, van der Meulen N, De Vries MA, Hazes M, Birnie E, Castro Cabezas M. Marked underdiagnosis and undertreatment of hypertension and hypercholesterolaemia in rheumatoid arthritis. Rheumatology (Oxford). 2016;55:1210-1216.

*73. González-Gay MA, González-Juanatey C. Inflammation and lipid profile in rheumatoid arthritis: bridging an apparent paradox. Ann Rheum Dis. 2014;73:12811283.

*Exciting and original editorial about the lipid paradox in rheumatoid arthritis. 74. Mathieu S, Motreff P, Soubrier M. Spondyloarthropathies: an independent cardiovascular risk factor? Joint Bone Spine. 2010;77:542-545. 
75. John H, Kitas G. Inflammatory arthritis as a novel risk factor for cardiovascular disease. Eur J Intern Med. 2012;23:575-579.

76. van Halm VP, van Denderen JC, Peters MJ, et al. Increased disease activity is associated with a deteriorated lipid profile in patients with ankylosing spondylitis. Ann Rheum Dis. 2006;65:1473-1477.

77. Tournadre A, Pereira B, Dubost JJ, et al. Management of dyslipidaemia in high-risk patients with recent-onset rheumatoid arthritis: targets still not met despite specific recommendations. Results from the ESPOIR cohort during the first five years of followup. Clin Exp Rheumatol. 2017;35:296-302.

78. Schmidt TJ, Aviña-Zubieta JA, Sayre EC, et al. Quality of care for cardiovascular disease prevention in rheumatoid arthritis: compliance with hyperlipidemia screening guidelines. Rheumatology (Oxford). 2018;57:1789-1794.

*79. Semb AG, Ikdahl E, Hisdal J, Olsen IC, Rollefstad S. Exploring cardiovascular disease risk evaluation in patients with inflammatory joint diseases. Int J Cardiol. 2016;223:331-336.

*Interesting paper about CVD risk in patients with inflammatory joint diseases. *80. López-Mejías R, Castañeda S, González-Juanatey C, et al. Cardiovascular risk assessment in patients with rheumatoid arthritis: The relevance of clinical, genetic and serological markers. Autoimmun Rev. 2016;15:1013-1030.

\section{* Recent review on the relevance of clinical, genetic and serological markers in RA.}

81. Rodríguez-Rodríguez L, González-Juanatey C, Palomino-Morales R, et al. TNFA 308 (rs1800629) polymorphism is associated with a higher risk of cardiovascular disease in patients with rheumatoid arthritis. Atherosclerosis. 2011;216:125-130. 82. Palomino-Morales R, Gonzalez-Juanatey C, Vazquez-Rodriguez TR, et al. A1298C polymorphism in the MTHFR gene predisposes to cardiovascular risk in 
rheumatoid arthritis. Arthritis Res Ther. 2010;12:R71.

83. López-Mejías R, Genre F, Remuzgo-Martínez S, et al. Vitamin D receptor GATG haplotype association with atherosclerotic disease in patients with rheumatoid arthritis. Atherosclerosis. 2016;245:139-142.

84. García-Bermúdez M, López-Mejías R, Genre F, et al. Interferon regulatory factor 5 genetic variants are associated with cardiovascular disease in patients with rheumatoid arthritis. Arthritis Res Ther. 2014;16:R146.

85. López-Mejías R, García-Bermúdez M, González-Juanatey C, et al. NFKB194ATTG ins/del polymorphism (rs28362491) is associated with cardiovascular disease in patients with rheumatoid arthritis. Atherosclerosis. 2012;224:426-429.

86. Gan Y, Gong Y, Tong X, et al. Depression and the risk of coronary heart disease: a meta-analysis of prospective cohort studies. BMC Psychiatry. 2014;14:371.

87. Batelaan NM, Seldenrijk A, Bot M, van Balkom AJ, Penninx BW. Anxiety and new onset of cardiovascular disease: a critical review and meta-analysis. Br J Psychiatry. 2016;208:223-231.

**88. Celano CM, Daunis DJ, Lokko HN, Campbell KA, Huffman JC. Anxiety disorders and cardiovascular disease. Curr Psychiatry Rep. 2016;18:101.

**Critical review and meta-analysis about the importance of anxiety in cardiovascular disease development.

89. Matchman F, Rayner L, Steer S, Hotopf M. The prevalence of depression in rheumatoid arthritis. Rheumatology (Oxford). 2013;52:2136-2148.

90. Van Dyke MM, Parker JC, Smarr KI, et al. Anxiety in rheumatoid arthritis. Arthritis Rheum. 2004;51:408-412.

91. Matchman F, Norton S, Scott DL, Steer S, Hotopf M. Symptoms of depression and anxiety predict treatment response and long-term physical health outcomes in 
rheumatoid arthritis: secondary analysis of randomized controlled trials. Rheumatology (Oxford). 2016;55:268-278.

**92. Piepoli MF, Hoes AW, Agewall S, et al. 2016 European Guidelines on cardiovascular disease prevention in clinical practice: the Sixth Joint Task Force of the European Society of Cardiology and Other Societies on Cardiovascular Disease Prevention in Clinical Practice (constituted by representatives of 10 societies and by invited experts). Eur Heart J. 2016;37:2315-2381.

**2016 Guidelines on cardiovascular disease prevention in clinical practice by the European Society of Cardiology and other 10 Societies on Cardiovascular Disease Prevention in Clinical Practice.

**93. Hollan I, Dessein PH, Ronda N, et al. Prevention of cardiovascular disease in rheumatoid arthritis. Autoimmun Rev. 2015;14:952-969.

**Interesting and beautiful paper about the prevention of CVD in rheumatoid arthritis.

*94. Hollan I, Meroni PL, Ahearn JM, et al. Cardiovascular disease in autoimmune rheumatic diseases. Autoimmun Rev. 2013;12:1004-1015.

*Similar manuscript on CVD in autoimmune rheumatic diseases beyond RA. 95. Weiner DE, Tighiouart H, Amin M, et al. Chronic kidney disease as a risk factor for cardiovascular disease and all-cause mortality: a pooled analysis of community-based studies. J Am Soc Neprol. 2004;15:1307-1315.

96. Matsushita K, van der Velde M, Astor BC, Woodwork M Levey AS. Association of estimated glomerular filtration rate and albuminuria with all-cause mortality and cardiovascular mortality: a collaborative meta-analysis of general population cohorts. Lancet. 2010;375(9731):2073-81. 
97. Dessein PH, Hsu H-C, Tsang L, et al. Kidney function, endothelial activation and atherosclerosis in black and white Africans with rheumatoid arthritis. PLoS One. 2015;10:e0121693.

98. Urruticoechea-Arana A, Martín-Martínez MA, Castañeda S, et al; CARMA Project Collaborative Group. Vitamin D deficiency in chronic inflammatory rheumatic diseases: results of the cardiovascular in rheumatology [CARMA] study. Arthritis Res Ther. 2015;17:211.

99. Grazio S, Naglić ĐB, Anić B, et al. Vitamin D serum level, disease activity and functional ability in different rheumatic patients. Am J Med Sci. 2015;349:46-49. 100. Pludowski P, Holick MF, Pilz S, et al. Vitamin D effects on musculoskeletal health, immunity, autoimmunity, cardiovascular disease, cancer, fertility, pregnancy, dementia and mortality — a review of recent evidence. Autoimmun Rev. 2013;12:976989.

101. Trelle S, Reichenbach S, Wandel S, et al. Cardiovascular safety of non-steroidal anti-inflammatory drugs: network meta-analysis. BMJ. 2011;342:c7086.

102. Lindhardsen J, Gislason GH, Jacobsen S, et al. Non-steroidal anti-inflammatory drugs and risk of cardiovascular disease in patients with rheumatoid arthritis: a nationwide cohort study. Ann Rheum Dis. 2014;73:1515-1521. 103. Aviña-Zubieta JA, Abrahamowicz M, De Vera MA, et al. Immediate and past cumulative effects of oral glucocorticoids on the risk of acute myocardial infarction in rheumatoid arthritis: a population-based study. Rheumatology (Oxford). 2013;52:68-75. 104. Aviña-Zubieta JA, Abrahamowicz M, Choi HK, et al. Risk of cerebrovascular disease associated with the use of glucocorticoids in patients with incident rheumatoid arthritis: a population-based study. Ann Rheum Dis. 2011;70:990-995. 
105. Choi HK, Hernán MA, Seeger JD, et al. Methotrexate and mortality in patients with rheumatoid arthritis: a prospective study. Lancet. 2002;359(9313):1173-1177. 106. Barnabe C, Martin BJ, Ghali WA. Systematic review and meta-analysis: antitumor necrosis factor $\alpha$ therapy and cardiovascular events in rheumatoid arthritis. Arthritis Care Res (Hoboken). 2011;63:522-529.

*107. Crowson CS, Matteson EL, Roger VL, Therneau TM, Gabriel SE. Usefulness of risk scores to estimate the risk of cardiovascular disease in patients with rheumatoid arthritis. Am J Cardiol. 2012;110:420-424.

*Manuscript that demonstrates that Framingham and Reynolds risk scores underestimate CVD risk in patients with RA of both genders, especially in older ages and in patients with positive rheumatoid factor.

*108. Solomon DH, Greenberg J, Curtis JR, et al. Derivation and internal validation of an expanded cardiovascular risk prediction score for rheumatoid arthritis: a Consortium of Rheumatology Researchers of North America Registry Study. Arthritis Rheumatol. 2015;67:1995-2003.

*Interesting paper about a new method to evaluate cardiovascular risk prediction in patients with rheumatoid arthritis in North America.

**109. Peters MJ, Symmons DP, McCarey D, et al. EULAR evidence-based recommendations for cardiovascular risk management in patients with rheumatoid arthritis and other forms of inflammatory arthritis. Ann Rheum Dis. 2010;69:325-331.

*EULAR evidence-based recommendations for cardiovascular risk management in patients with rheumatoid arthritis and other inflammatory joint arthritis. 110. Arts EEA, Popa CD, Den Broeder AA, et al. Prediction of cardiovascular risk in rheumatoid arthritis: performance of original and adapted SCORE algorithms. Ann Rheum Dis. 2016;75:674-680. 
**111. Agca R, Heslinga SC, Rollefstad S, et al. EULAR recommendations for cardiovascular disease risk management in patients with rheumatoid arthritis and other forms of inflammatory joint disorders: 2015/2016 update. Ann Rheum Dis. 2017;76:1728.

**The most recent EULAR recommendations for cardiovascular risk management in patients with rheumatoid arthritis and other IJDs.

112. Wiersma T, Smulders YM, Stehouwer CD, Konings KT, Lanphen J. [Summary of the multidisciplinary guideline on cardiovascular risk management (revision 2011)]. Ned Tijdschr Geneeskd. 2012;156:A5104.

113. Eder L, Chandran V, Gladman DD. The Framingham Risk Score underestimates the extent of subclinical atherosclerosis in patients with psoriatic disease. Ann Rheum Dis. 2014;73:1990-1996.

**114. Stone NJ, Robinson JG, Lichtenstein AH, et al; American College of Cardiology/American Heart Association Task Force on Practice Guidelines. 2013 ACC/AHA guideline on the treatment of blood cholesterol to reduce atherosclerotic cardiovascular risk in adults: a report of the American College of Cardiology/American Heart Association Task Force on Practice Guidelines. Circulation. 2014;129(25 Suppl 2):S1-45.

\section{**Practical Guidelines of American College of Cardiology and American Heart} Association on the treatment of hypercholesterolemia in adults.

115. Loza E, Lajas C, Andreu JL, et al. Consensus statement on a framework for the management of comorbidity and extra-articular manifestations in rheumatoid arthritis. Rheumatol Int. 2015;35:445-458. 
**116. Jacobson TA, Maki KC, Orringer CE, et al; NLA Expert Panel. National Lipid Association Recommendations for Patient-Centered Management of Dyslipidemia: Part 2. J Clin Lipidol. 2015;9(6 Suppl):S1-122.

**USA National Lipid Association Recommendations for the Management of

\section{Dyslipidemia.}

117. Mozaffarian D, Ludwig DS. The 2015 US Dietary Guidelines: Lifting the ban on total dietary fat. JAMA. 2015;313:2421-2422.

118. Eckel RH, Jakicic JM, Ard JD, et al, American College of Cardiology/

American Heart Association Task Force on Practice Guidelines. 2013 AHA/ACC guideline on lifestyle management to reduce cardiovascular risk: a report of the American College of Cardiology/American Heart Association Task Force on Practice Guidelines. J Am Coll Cardiol. 2014;63(25 Pt B):2960-2984.

119. Proudman SM, JamesMJ, Spargo LD, et al. Fish oil in recent onset rheumatoid arthritis: a randomised, double-blind controlled trial within algorithm-based drug use. Ann Rheum Dis. 2015;74:89-95.

120. Santangelo C, Vari R, Scazzocchio B, et al. Anti-inflammatory Activity of Extra Virgin Olive Oil Polyphenols: Which Role in the Prevention and Treatment of ImmuneMediated Inflammatory Diseases? Endocr Metab Immune Disord Drug Targets. 2018;18:36-50.

121. Lee YL, Hu HY, Chou P, Chu D. Dental prophylaxis decreases the risk of acute myocardial infarction: a nationwide population-based study in Taiwan. Clin Interv Aging. 2015;10:175-182.

122. Reichert S, Schlitt A, Beschow V, et al. Use of floss/ interdental brushes is associated with lower risk for new cardiovascular events among patients with coronary heart disease. J Periodontal Res. 2015;50:180-188. 
*123. Martín-Martínez MA, González-Juanatey C, Castañeda S, et al.

Recommendations for the management of cardiovascular risk in patients with rheumatoid arthritis: scientific evidence and expert opinion. Semin Arthritis Rheum. 2014;44:1-8.

*Practical recommendations for the management of cardiovascular risk in Spanish patients with rheumatoid arthritis based on scientific evidence and expert opinion. 124. González-Gay MA, González-Juanatey C. Inflammation: NSAIDs and cardiovascular risk in arthritis. Nat Rev Cardiol. 2017;14:69-70.

125. Panoulas VF, Douglas KM, Milionis HJ, et al. Prevalence and associations of hypertension and its control in patients with rheumatoid arthritis. Rheumatology (Oxford). 2007;46:1477-1482.

126. Provan SA, Semb AG, Hisdal J, et al. Remission is the goal for cardiovascular risk management in patients with rheumatoid arthritis: a cross-sectional comparative study. Ann Rheum Dis. 2011;70:812-817.

127. Micha R, Imamura F, Wyler von Ballmoos M, et al. Systematic review and metaanalysis of methotrexate use and risk of cardiovascular disease. Am J Cardiol.

2011;108:1362-1370.

128. Greenberg JD, Kremer JM, Curtis JR, et al.; CORRONA Investigators. Tumour necrosis factor antagonist use and associated risk reduction of cardiovascular events among patients with rheumatoid arthritis. Ann Rheum Dis. 2011;70:576-582.

*129. Williams B, Mancia G, Spiering W, et al; ESC Scientific Document Group . 2018 ESC/ESH Guidelines for the management of arterial hypertension. Eur Heart J. 2018;39:3021-3104.

**2018 European Guidelines for the management of arterial hypertension by the ESC/ESH Societies. 
**130. Whelton PK, Carey RM, Aronow WS, et al. 2017

ACC/AHA/AAPA/ABC/ACPM/AGS/APhA/ASH/ASPC /NMA/PCNA guideline for the prevention, detection, and management of high blood pressure in adults: a report of the American College of Cardiology/American Heart Association Task Force on Clinical Practice Guidelines. J Am Coll Cardiol. 2018;15:e127-e248.

**2017 American Guidelines for the management of arterial hypertension by the ACC/AHA/AAPA/ABC/ACPM/AGS/APhA/ASH/ASPC /NMA/PCNA Societies.

**131. Catapano AL, Graham I, De Backer G, et al; ESC Scientific Document Group. 2016 ESC/EAS Guidelines for the Management of Dyslipidaemias. Eur Heart J. 2016;37:2999-3058.

**2016 ESC/EAS Guidelines for the Management of Dyslipidaemias.

*132. Cholesterol Treatment Trialists' (CTT) Collaboration, Baigent C, Blackwell L, Emberson J, et al. Efficacy and safety of more intensive lowering of LDL cholesterol: a meta-analysis of data from 170,000 participants in 26 randomised trials. Lancet. 2010;376(9753):1670-1681.

*Clinical trial demonstrating that intensive treatment to reduce LDL-cholesterol produce further reductions in the incidence of heart attack, revascularisation, and ischaemic stroke than standardized regimens.

133. Semb AG, Holme I, Kvien TK, Pedersen TR. Intensive lipid lowering in patients with rheumatoid arthritis and previous myocardial infarction: an explorative analysis from the incremental decrease in endpoints through aggressive lipid lowering (IDEAL) trial. Rheumatology (Oxford). 2011;50:324-329.

134. 2019 ESC/EAS guidelines for the management of dyslipidaemias: Lipid modification to reduce cardiovascular risk. Authors/Task Force Members; ESC 
Committee for Practice Guidelines (CPG); ESC National Cardiac Societies. Atherosclerosis. 2019;290:140-205.

135. Stock J. News from ESC congress 2019: New ESC/EAS guidelines for dyslipidaemia management published. Atherosclerosis. 2019 Oct 5. pii: S00219150(19)31500-X. doi: 10.1016/j.atherosclerosis.2019.09.013.

*136. Schwartz GG, Steg PG, Szarek M, et al; ODYSSEY OUTCOMES Committees and Investigators. Alirocumab and Cardiovascular Outcomes after Acute Coronary Syndrome. N Engl J Med. 2018;379:2097-2107.

\section{*Clinical Trial demonstrating the efficacy of alirocumab to prevent recurrent} ischemic cardiovascular events in patients suffering Acute Coronary Syndrome. 137. González-Gay MA, González-Juanatey C. Cardiovascular risk factor assessment: still an unmet need in chronic inflammatory diseases. Heart. 2016;102:1937-1939. 138. Udell JA, Zawi R, Bhatt DL, et al. Asocciation between influenza vaccination and cardiovascular outcomes in high-risk patients: a meta-analysis. JAMA. 2013;310:17111720.

139. European Guidelines on cardiovascular disease prevention in clinical practice (version 2012): the Fifth Joint Task Force of the European Society of Cardiology and Other Societies on Cardioyascular Disease Prevention in Clinical Practice (constituted by representatives of nine societies and by invited experts). Eur J Prev Cardiol. 2012;19:585-667.

140. Vlachopoulos CV, Terentes-Printzios DG, Aznaouridis KA, Pietri PG, Stefanadis CI. Association between pneumococcal vaccination and cardiovascular outcomes: a systematic review and meta-analysis of cohort studies. Eur J Prev Cardiol. 2015;22:1185-1199. 


\section{FIGURE LEGEND}

Figure 1. Overview showing the relationship between genetics, traditional cardiovascular risk factors, chronic inflammation, inactivity and emergent cardiovascular risk factors in the pathogenesis of the cardiovascular disease in inflammatory joint diseases.

Footnotes: CV: cardiovascular; CVRFs: cardiovascular risk factors; NSAIDs: nonsteroidal anti-inflammatory drugs. Continuous lines indicate consistent or evidenced relationship; dashed lines indicate less recognized or consistent relationship. Modified from Castañeda et al. [Best Practice 2016; ref. 12*]. 


\section{TABLES}

Table 1. Advantages and disadvantages of different non-invasive imaging techniques used in the diagnosis of cardiovascular disease in inflammatory joint diseases.+

\begin{tabular}{|c|c|c|c|}
\hline Imaging technique & Advantages & Disadvantages & $\begin{array}{l}\text { Experience in } \\
\text { rheumatology }\end{array}$ \\
\hline $\begin{array}{l}\text { Arterial stiffness } \\
\text { assessment, ABI }\end{array}$ & $\begin{array}{l}\text { Cheap, innocuous } \\
\text { No radiation exposure } \\
\text { No contrast needed }\end{array}$ & $\begin{array}{l}\quad \text { Laborious } \\
\text { Not very sensitive } \\
\text { Inter-observer } \\
\text { variability } \\
\text { Not sufficiently } \\
\text { validated }\end{array}$ & + \\
\hline Carotid ultrasound & $\begin{array}{l}\text { Simple, cheap, rapid, } \\
\text { innocuous \& } \\
\text { reproducible } \\
\text { No } \\
\text { contrast/venipuncture } \\
\text { Large evidence } \\
\text { supported } \\
\text { No radiation exposure } \\
\end{array}$ & $\begin{array}{l}\text { Possible inter- } \\
\text { observer variability } \\
\text { Longitudinal studies } \\
\text { are scarce }\end{array}$ & \\
\hline $\begin{array}{l}\text { Computed } \\
\text { tomography } \\
\text { (CT) }\end{array}$ & $\begin{array}{c}\text { Rapid } \\
\text { Reproducible } \\
\text { Evidence based on } \\
\text { non-IJD patients }\end{array}$ & $\begin{array}{c}\text { Reasonably expensive } \\
\text { Less sensitive than } \\
\text { US in IJD } \\
\text { Dependent on } \\
\text { radiologists } \\
\text { Radiation exposure } \\
\text { Contraindicated in } \\
\text { allergic to contrast } \\
\text { and in severe CKD }\end{array}$ & ++ \\
\hline $\begin{array}{l}\text { Cardiac magnetic } \\
\text { resonance }\end{array}$ & $\begin{array}{c}\text { Assessment of } \\
\text { multiple measures of } \\
\text { ACVD } \\
\text { Reproducible } \\
\text { Evaluation of } \\
\text { additional heart/CV } \\
\text { manifestations } \\
\text { No radiation exposure }\end{array}$ & $\begin{array}{c}\text { Expensive } \\
\text { Limited evidence } \\
\quad \text { nowadays } \\
\text { Gd contraindicated if } \\
\text { severe CKD } \\
\text { Contraindicated in } \\
\text { subjects with some } \\
\text { metal devices } \\
\text { Claustrophobia } \\
\end{array}$ & ++ \\
\hline $\begin{array}{l}\text { Positron emission } \\
\text { tomography }\end{array}$ & $\begin{array}{c}\text { Reproducible } \\
\text { Evaluation of } \\
\text { additional myocardium } \\
\text { alterations } \\
\end{array}$ & $\begin{array}{c}\text { Expensive } \\
\text { Radiation exposure } \\
\text { Long scan times } \\
\text { Not widely available } \\
\end{array}$ & + \\
\hline
\end{tabular}

Abbreviations: II Arterial stiffness assessment includes aortic pulse wave velocity and augmentation index. Similar techniques are: aortic distensibility and ABI (anklebrachial elasticity index).

ACS: acute coronary syndrome; ACVD: atherosclerotic cardiovascular disease; CKD: chronic kidney disease; CV: cardiovascular; Gd: gadolinium; IJD: inflammatory joint diseases; $(+/+++)=$ semi-quantitative evaluation in rheumatology.

Modified from Fent et al. [ref. 21**]. 
Table 2. Emergent factors of cardiovascular risk.

\section{Main emergent factors of CV risk non included in current risk assessment scales}

\section{A) Psychological and social factors}

Socioeconomic and cultural factors

Psychosocial factors, education level

Major mood disturbances: depression and anxiety

Family and/or job stress

Physical inactivity

\section{B) Organic diseases}

Chronic kidney disease/renal failure

Obstructive sleep apnea syndrome

Diseases associated with thrombophilia

Hypothyroidism

Chronic obstructive pulmonary disease

Periodontitis (not completely proved)

\section{C) Miscellany conditions}

Low vitamin D levels

Hyperhomocysteinemia

Hyperuricemia

Influenza epidemics

Erectile dysfunction

Disturbances in gut microbiota (?)

Abbreviations: CV: cardiovascular 
Table 3. Cardiovascular disease risk categories and recommended lipid lowering preventive treatment.

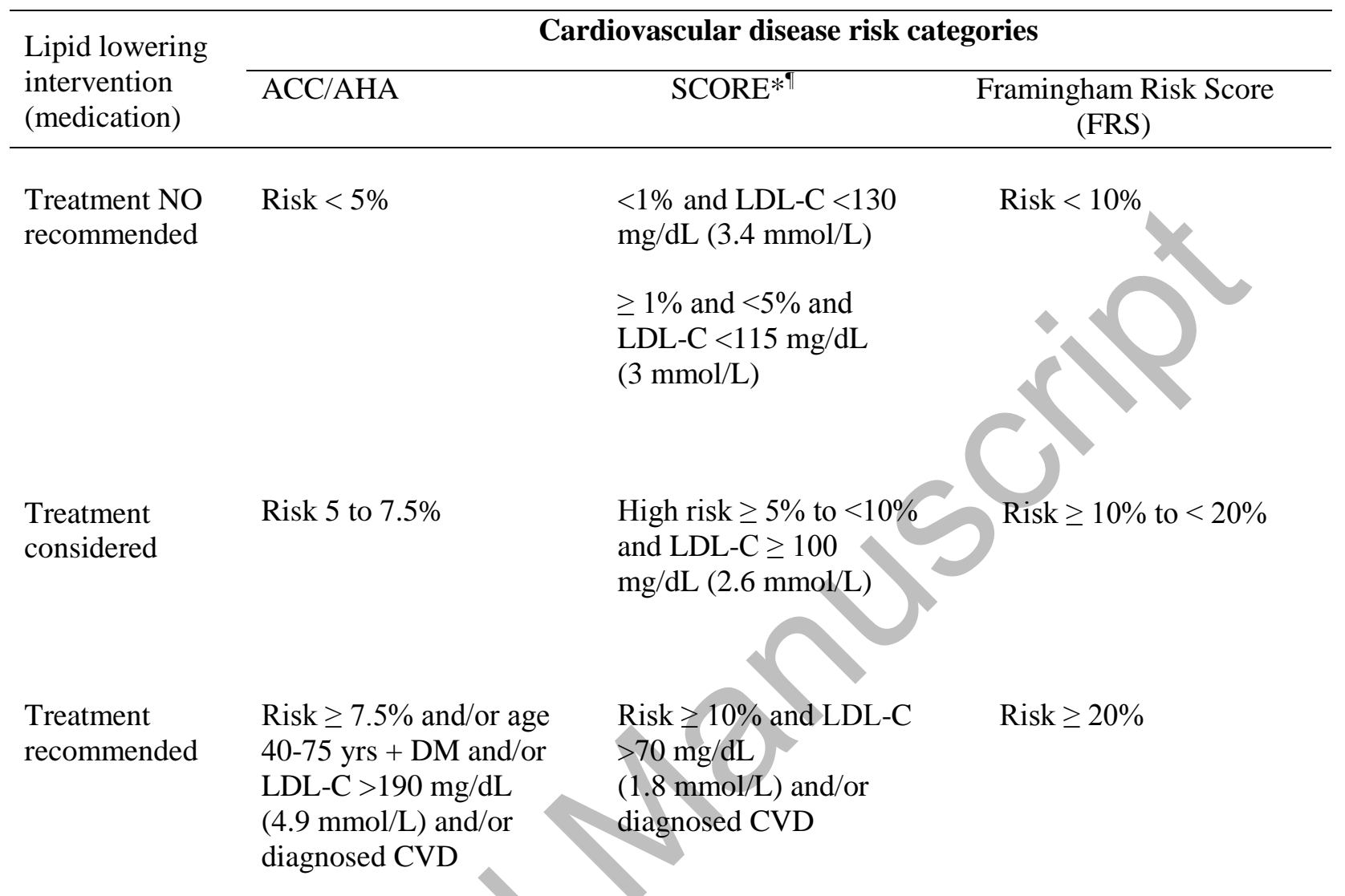

Abbreviations: ACC/AHA: American College of Cardiology/American Heart Association; CV: cardiovascular; CVD: cardiovascular disease; DM: diabetes mellitus; FRS: Framingham Risk Score; IJD: Inflammatory joint diseases; LDL-C: low density lipoprotein cholesterol; SCORE: Systematic Coronary Risk Evaluation.

*SCORE classifies patients differently as they come from countries with very-high, high, moderate or low CV risk. In IJD, in particular in patients with RA, modified SCORE is normally used, which is obtained by multiplying the result obtained by a correction factor of 1.5 .

II Overall, the THERAPEUTIC GOALS to start/continue a lowering lipid treatment in IJD patients by SCORE scale assessment are the following: Low risk: LDL always $<130 \mathrm{mg} / \mathrm{dL}$ ( $3.4 \mathrm{mmol} / \mathrm{L})$; Moderate risk: LDL < $115 \mathrm{mg} / \mathrm{dL}$ ( $3 \mathrm{mmol} / \mathrm{L})$; High risk: LDL < $100 \mathrm{mg} / \mathrm{dL}(2.6$ $\mathrm{mmol} / \mathrm{L})$; Very-High risk: LDL $<70 \mathrm{mg} / \mathrm{dL}(1.8 \mathrm{mmol} / \mathrm{L})$ or reduction LDL-C levels $\geq 50 \% \mathrm{vs}$. levels before therapy.

Modified from Semb et al. [ref. 79*]. 
Table 4. Unmet needs in cardiovascular risk evaluation in inflammatory joint diseases.

Abbreviations: AS: ankylosing spondylitis; CV: cardiovascular; CVD: cardiovascular disease; CVE: cardiovascular event; CVRF: cardiovascular risk factors; GP: general practitioners; HF: heart failure; IJD: inflammatory joint diseases; PAD: peripheral arterial disease; PsA: psoriatic arthritis; RA: rheumatoid arthritis; T2T: treat to target strategy.

\section{Main unmet needs in CV risk assessment}

\section{1) Epidemiology of CVD in IJDs}

- Evaluation of the incidence of CVD \& CVE in early RA, as well as in early AS and PsA

- Study of the prevalence of $H F$ and PAD in patients with IJD, especially in AS and PSA

2) Subclinical atherosclerosis

- Evaluation of the best method for early detection of subclinical atherosclerosis in IJDs

\section{3) Genetics}

- Expand the knowledge of CVD genetics in patients with IJD, especially AS and PsA

\section{4) $\mathrm{CV}$ risk factors}

- Potentiate campaigns for early detection of traditional CVRFs

- Assess the real impact of mood disorders in CV risk scales in IJD patients

- Study the possible relationship between periodontal disease and CVD in IJDs

5) Anti-rheumatic medication and CVD

- Design longitudinal studies to identify the incidence of long-term CVE in patients with IJDs under biologics or small molecules and T2T control strategy

- Evaluate CV safety in clinical trials testing new biologics and advanced therapies

6) Stratification of $\mathrm{CV}$ risk in IJD patients

- Long-term validation of CV risk algorithms in RA patients

- Establish specific CV risk scores for AS and PsA

7) Imaging

- Design longitudinal studies to confirm the evolution of atheroma plaques and their impact on the reclassification of patients with IJDs

\section{8) Prevention and therapy of CVD}

- Improve the adherence to CV therapy of patients with IJD and CVRFs

- Potentiate the relationship with GPs to improve the attention to these patients

- Reinforce the interaction between different disciplines to improve monitoring and

follow-up of these patients 


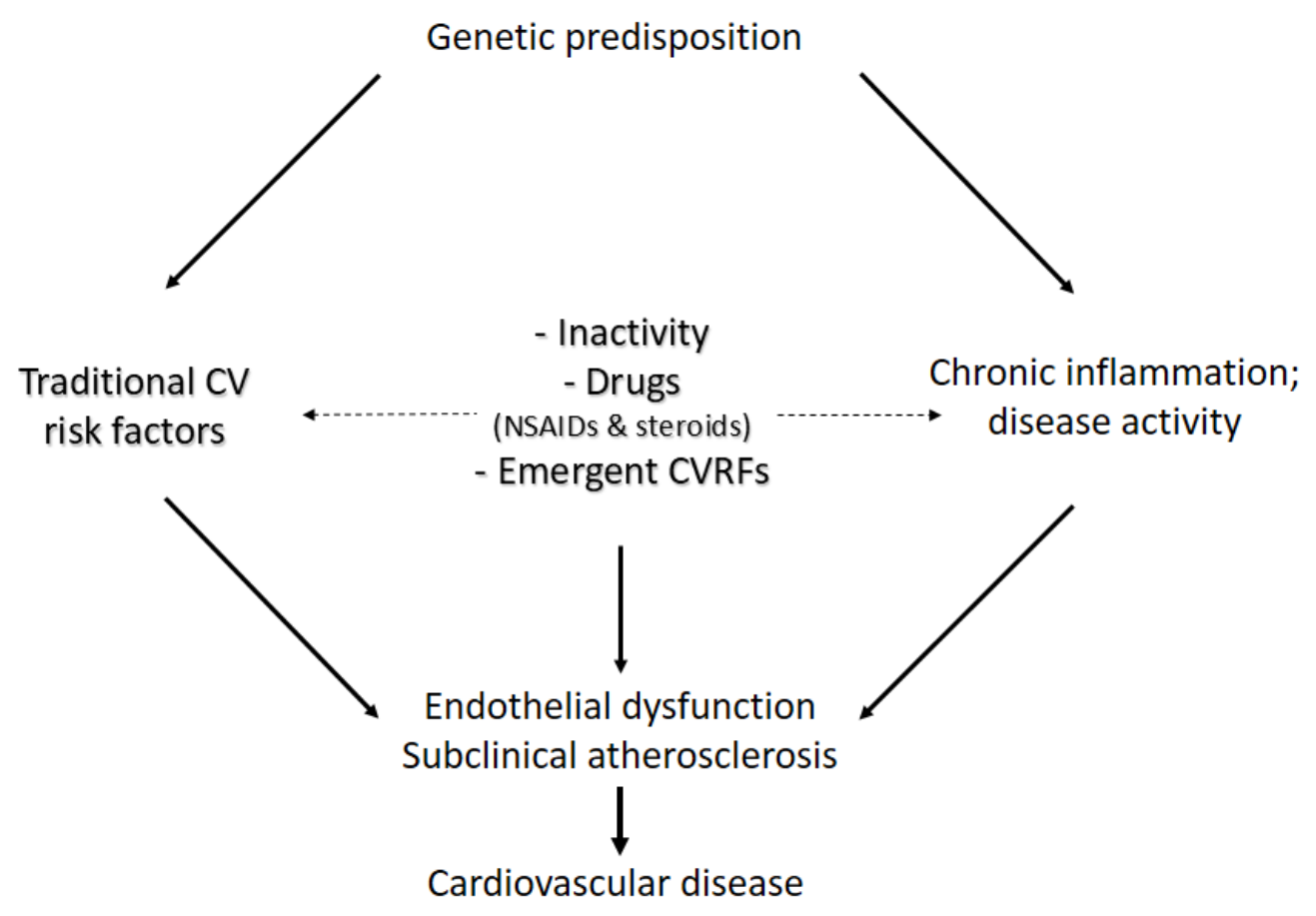

fig 1 